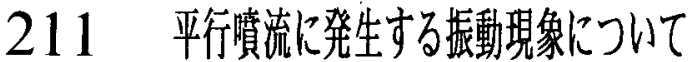

\section{大島貴充 （愛知工業大学）}

On the Vibration generated in the Parallel Jet

Takamitsu Ohshima, Aichi Institute of Technology

The injection of a two-dimensional free jet into a stationary fluid results in the formation of two parallel vortex streets whose vortexes are located alternately when the Reynoldos number is determined by the velocity of the jet and the nozzle width is in the range of $10^{2} \sim 10^{3}$.

To study the behavior of such vortex street, we used milk as a tracer and recorded the pattern of the flow, i.e. the vibration, of two vortex street and the central axis of the jet.

Furthermore, we recorded the power spectrum of the pressure changes in the flow field using pressure sensors, and studied the behavior of the vibrating flow jet field. In addition, assuming that the flow is that of an ldeal fluid, we represented the flow fleld using Euler's kinetic equation and a linear approximation equation of continuity, and demonstrated that the two parallel jet vibrated. We also present the vortex street generated by the parallel jet.

Key Word: Parallel Jet, Parallel Flow, Flou Induced Vibration, Internal Wave Model, Free Jet, Flow Pattewn, Vortex Dynamics, Unsteady Flow, Rectangular Jet, Tracer Method

\section{1.はじめに}

同種の静止流体中へ喷出する二次元自由噴流は、喷流 の中心湶に直角方向に规則的な掁動をすることがよく知 られている。この現象の発生原因については、噴流両側 に形成される渦列に起因するとする説、自由剪断流とし の噴流の安定性にもとずくとする説など数々の説が提唱 されているが、定説はない。本研究は上記の唄流の振動 現象は、噴流が形成する速度場に発生する内部波（波動 形港乱）に起因するものと考える立場から、内部波の数 学モテルから導かれる㖵流の性質を数值解析によって求 め、前記の考元方の妥当性を检討したものである。噴流 の可視化結果との対比は、振動する喷流の形状およびそ の時間推移による変化の模様を主とした定性的側面から おこない、また噴流の振動している流扎場のパワースペ クトルの测定結果は、その一例を示すにとどめ詳細につ いては本報では言及しない。噴流の振動数、振動数と嗢 流の蝠など、櫴流の振動している流れ場のパワースペク トル、クロススペクトル解析結果などの定量的側面につ いては別報にゆずる。

\section{2. モデルの構成}

流体は完全流体とし、流れ場には次の仮定をおく。

1，流れ場は二次元とする。

2. 筧乱が発生する以前の定常流（主流）は、流 れの方向 $(\mathrm{x}$ 方向) の速度が流れの方向に直 な方向（y 方向）に变化する平行流とする。

3. 筧乱（速度変動）の大きさは主流に比べて 1
位の铰小量とする。

基碳方程式はオイラーの連動方程式と連続の式で、デ カルト座標系で以下のようである。

$$
\begin{aligned}
& \frac{\partial u}{\partial x}+\frac{\partial v}{\partial y}=0 \\
& \frac{\partial u}{\partial t}+u \frac{\partial u}{\partial x}+v \frac{\partial u}{\partial y}=-\frac{\partial p}{\partial x} \\
& \frac{\partial v}{\partial t}+u \frac{\partial v}{\partial x}+v \frac{\partial v}{\partial y}=-\frac{\partial p}{\partial y} \\
& u, v: \text { それぞれ速度の } x, y \text { 成分 } \\
& \mathrm{p}: \text { : 運動学的压力 (压力/密度) } \\
& \mathrm{t}: \text { 時間 }
\end{aligned}
$$

ここで、流れは定常な噴流に微小掼乱を重複した形で 表しうる.と考え: 各速度成分を次式で表す（平行流の仮 定により $v$ の定常成分はない）。

$$
\begin{aligned}
& \mathrm{u}=\overline{\mathrm{u}}(\mathrm{y})+\widetilde{\mathrm{u}}(\mathrm{x}, \mathrm{y}, \mathrm{t}) \\
& \mathrm{v}=\widetilde{\mathrm{v}}(\mathrm{x}, \mathrm{y}, \mathrm{t}) \\
& \mathrm{p}=\mathrm{p}_{0}+\widetilde{\mathrm{p}}(\mathrm{x}, \mathrm{y}, \mathrm{t})
\end{aligned}
$$

ここで、 $\mathrm{u}(\mathrm{y})$ は定常な㬈流で $\mathrm{y}$ のみの関数、别は定 常な㧧流（主流）の圧力。また記号一で平均值、〜で平 均値まわりに㚆動する掼乱をあらわす。

(4)を(1)〜 (3)に代入し、2 位以下の微小量を無視す れば、掼乱を記述する線形化された次の 3 個の方程式を うる。なお $u(x, y, t)$ などにおける $(x, y, t)$ の記述は 省略する。 


$$
\begin{aligned}
& \frac{\partial \widetilde{u}}{\partial x}+\frac{\partial \widetilde{v}}{\partial y}=0 \\
& \frac{\partial \widetilde{\mathrm{u}}}{\partial t}+\overline{\mathrm{u}} \frac{\partial \widetilde{\mathrm{u}}}{\partial \mathrm{x}}+\widetilde{v} \frac{\partial \bar{u}}{\partial \mathrm{y}}+\frac{\partial \widetilde{p}}{\partial \mathrm{x}}=0 \\
& \frac{\partial \widetilde{v}}{\partial \mathrm{t}}+\overline{\mathrm{u}} \frac{\partial \widetilde{v}}{\partial \mathrm{x}}+\frac{\partial \widetilde{\mathrm{p}}}{\partial \mathrm{y}}=0
\end{aligned}
$$

この方程式群は実係数の線形微分方程式である。この 方程式の実数解を求めるために、複素数解 $\widehat{\mathrm{u}}, \overparen{\mathrm{v}} 、 \widehat{\mathrm{p}}$ 次のような波動形拱乱の形におく。

$$
\begin{aligned}
& \widehat{u}=v(y) \times \mathrm{e}^{\mathrm{i} \alpha(u-c t)} \\
& \widehat{v}=v(y) \times \mathrm{e}^{\mathrm{i} \alpha(u-c t)} \\
& \widehat{p}=P(y) \times \mathrm{e}^{\mathrm{i} \alpha(u-c t)}
\end{aligned}
$$

ここに、 $\mathrm{i}$ は虚数単位、U, V, P は y のみの複素関数 、 $\alpha$ は波数（実数）、 $\mathrm{c}$ は波動速度（複素数）で ある。したがって $c=c_{r}+i c$ ，とかけ、c，の正負 はそれぞれ時間経過による掼乱の増幅、減哀に対応する 。また記号一は複素数解を表す。

(8)を (5)〜 (7) に代入するとU，V，P を支配する次 の方程式群が得られる。

$$
\begin{aligned}
& \text { i } \alpha U+\frac{d V}{d y}=0 \\
& \text { i } \alpha(\bar{u}-c) U+v \frac{d \bar{u}}{d y}+i \alpha P=0 \\
& \text { i } \alpha(\bar{u}-c) v+\frac{d p}{d y}=0
\end{aligned}
$$

この 3 式より U, P を消去すると V に関する次式が 得られる。

$$
\frac{\mathrm{d}^{2} \mathbf{v}}{\mathrm{dy^{2 }}}=\left[\frac{1}{\bar{u}-\mathrm{c}} \times \frac{\mathrm{d}^{2} \bar{u}}{\mathrm{dy}^{2}}+\alpha^{2}\right] \mathbf{v}
$$

この式は Rayleigh の式としてよく知られているもので 、 $\mathrm{u}(\mathrm{y})$ なる速度分布をもつ非粘性流体の平行流の安定 性を支配する基礎方程式である。適切な境界条件のもと て、任意の $\alpha$ の値に関して解け、 $\alpha$ と および $\mathbf{v}(\mathrm{y})$ の 関保を与える。膡乱を支配する方程式は実保数線形微分 方程式であるから、仮定した複素解の複素共役も解であ る。したがって摜乱の実数解が求まる。実際の嘖流の速 度分布は、下流にいくにしたがって広がり、速度分布の 形状が変化する。長方形の噴出口直後の方形の速度分布 から、図 $1^{(1)}$ に示すような速度分布へ移行して、しば

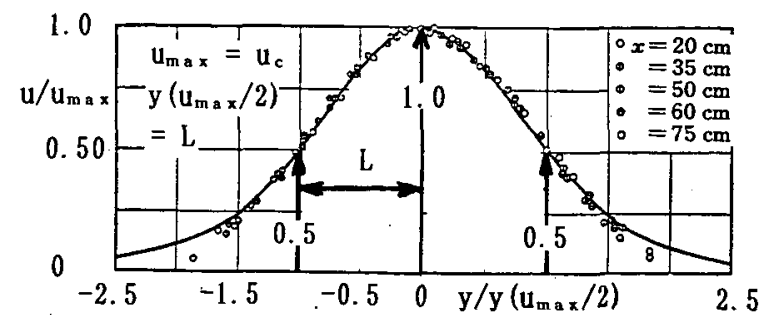

Fig. 1 Velocity distribution in a two-dimensional , turbulent jet. Measurement due to Foerthman.
らくの間この速度分布の形状が維持される。速度分布の y方向への広がりの小さいところを、平行流れであると してモデル化する。このような速度分布は一般に次のよ うな式で表される(2)。

$$
\bar{u}(y)=u_{c} \operatorname{sech}^{2}(k y)
$$

ここで、 $\mathrm{u}_{\mathrm{c}}$ は噴流の中心軸上の速度、 $\mathrm{k}$ は噴流の $\mathrm{y}$ 方 向への広がりを表すバラメータである。図に示すような 、嘖流の中心軸上の速度 $\mathrm{u}_{\mathrm{c}}$ と半值幅 $\mathrm{L}$ をもちいて無 次元化すると、定常な噴流の速度分布の式と Rayleigh の式は次のように表される。

$$
\bar{u}_{\mathrm{n}}(\mathrm{y})=\operatorname{sech}^{2}\left(\mathrm{k}_{\mathrm{n}} \mathrm{y}_{\mathrm{n}}\right)
$$

$\frac{d^{2} V_{n}}{d y^{2}}=\left\{\frac{1}{\overline{u_{n}}-c_{n}} \times \frac{d^{2} \overline{u_{n}}}{d y^{2}}+\alpha_{n}{ }^{2}\right\} V$

ここで, $u_{n}(y)=u(y) / u_{c}, y_{n}=y / L$.

$$
\mathrm{k}_{\mathrm{n}}=\mathrm{kL}=\cosh ^{-1} \sqrt{2}
$$

（14）を(15)に代入すると次式を得る。

$$
\begin{aligned}
& \frac{\mathrm{d}^{2} V_{\mathrm{n}}}{\mathrm{dy}_{\mathrm{n}}^{2}}=\left(\frac{6 \mathrm{k}_{\mathrm{n}}{ }^{2} \operatorname{sech}^{2}\left(\mathrm{k}_{\mathrm{n}} \mathrm{y}_{\mathrm{n}}\right)}{\operatorname{sech}^{2}\left(\mathrm{k}_{\mathrm{n}} \mathrm{y}_{\mathrm{n}}\right)-\mathrm{c}_{\mathrm{n}}}+\alpha_{\mathrm{n}}\right] \mathrm{V}_{\mathrm{n}} \\
& \text { ここで, } \mathrm{V}_{\mathrm{n}}=\mathrm{V}_{\mathrm{n}}\left(\mathrm{y}_{\mathrm{n}}\right)=\mathrm{V}(\mathrm{y}) / \mathrm{u}_{\mathrm{c}}, \mathrm{c}_{\mathrm{n}}=\mathrm{c} / \mathrm{u}_{\mathrm{c}} 、 \\
& \alpha_{\mathrm{n}}=\alpha \mathrm{L}
\end{aligned}
$$

（16）式を解き、 $c_{1}=0$ 、すなわち膡乱が增幅も诚衰 もしないときの、 $\mathrm{V}_{\mathrm{n}}\left(\mathrm{y}_{\mathrm{n}}\right)$ の実数解を求める。 $\mathrm{C}_{\mathrm{n}}$ は実 数部のみとなるので、以後 $c_{n r}$ を $\mathrm{c}$ とする。 この実数解には次の二つがある。

$$
\begin{aligned}
& V_{n}\left(y_{n}\right)=A \operatorname{sech}^{2}\left(k_{n} y_{n}\right) \quad(17-1) \\
& \text { ただし、 } \alpha_{n}=2 k_{n}, c=(2 / 3) u_{c} \\
& V_{n}\left(y_{n}\right)=A \sinh \left(k_{n} y_{n}\right) \operatorname{sech}^{2}\left(k_{n} y_{n}\right) \quad(17-2) \\
& \text { ただし、 } \alpha_{n}=k_{n}, c=(2 / 3) u_{c}
\end{aligned}
$$

(17-1) は $\mathrm{y}_{\mathrm{n}}$ について偶関数、(17-2)は $\mathrm{y}_{\mathrm{n}}$ について奇 関数である。これらの $\mathbf{V}_{n}\left(y_{n}\right)$ をもちいて (9)〜 (11) か ら $U_{n}\left(y_{n}\right) 、 P_{n}\left(y_{n}\right)$ が求まり、その結果を(8) へ代入 すれば複素数解 $\widehat{\mathrm{u}} 、 \widehat{\mathrm{v}} 、 \widehat{\mathrm{p}}$ が求まる。その共役も解で あるから、実数解 $\widetilde{\mathrm{u}} 、 \widetilde{\mathrm{v}} 、 \widetilde{\mathrm{p}}$ が求まる。この実数解に 定常な噴流の速度分布を加えれば、非定常な噴流の流れ 場の波動モデルが求まる。

$\mathrm{V}_{\mathrm{n}}\left(\mathrm{y}_{\mathrm{n}}\right)$ が偶関数の場合、波動モデルは次式となる。 $\mathrm{u}=\overline{\mathrm{u}}+\widetilde{\mathrm{u}}$

$$
=\operatorname{sech}^{2}\left(k_{n} y_{n}\right)
$$

$+A \sinh \left(k_{n} y_{n}\right) \operatorname{sech}^{3}\left(k_{n} y_{n}\right) \sin \left\{\alpha_{n}\left(x_{n}-c t_{n}\right)\right\}$

$v=\widetilde{v}=A \operatorname{sech}^{2}\left(k_{n} y_{n}\right) \cos \left\{\alpha_{n}\left(x_{n}-c t_{n}\right)\right\}$

$\mathrm{p}=\mathrm{p}_{\mathrm{o}}$

$+A C \sinh \left(k_{n} y_{n}\right) \operatorname{sech}^{3}\left(k_{n} y_{n}\right) \sin \left\{\alpha_{n}\left(x_{n}-c t_{n}\right)\right\}$

$\mathrm{V}_{\mathrm{n}}\left(\mathrm{y}_{\mathrm{n}}\right)$ が奇関数の場合、波動モテルは次式となる。 $\mathrm{u}=\overline{\mathrm{u}}+\widetilde{\mathrm{u}}$

$=\operatorname{sech}^{2}\left(k_{n} y_{n}\right)$

$+A\left\{\sinh ^{2}\left(k_{n} y_{n}\right)-1\right\} \operatorname{sech}^{3}\left(k_{n} y_{n}\right) \sin \left\{\alpha_{n}\left(x_{n}-c t_{n}\right)\right\}$ $\left.v=\widetilde{v}=A \sinh \left(k_{n} y_{n}\right) \operatorname{sech}^{2}\left(k_{n} y_{n}\right) \cos \left\{\alpha_{n}\left(x_{n}-c t_{n}\right)\right\}\right\}$ 
$\mathrm{p}=\mathrm{p}_{\mathrm{o}}$

$+A c\left\{\sinh ^{2}\left(k_{n} y_{n}\right)-1\right\} \operatorname{sech}^{3}\left(k_{n} y_{n}\right) \sin \left\{\alpha_{n}\left(x_{n}-c t_{n}\right)\right\}$ ただし、 $\mathrm{t}_{\mathrm{n}}=\mathrm{t} /\left(\mathrm{L} / \mathrm{u}_{\mathrm{c}}\right)$

(18) の形の解が、互い違い形 (千鳥形) の渦列に対応し 、(19)の形の解が対称形の渦列に対応する。 なお(16) 式 から $\alpha_{\mathrm{n}}$ のある範囲にわたって $\mathrm{c}_{\mathrm{i}}>0$ の摜乱の増幅解 が、 $\alpha_{\mathrm{n}}$ のある值に対応して数值的に得られることが知 られているが、そのことについては別報で述べる。

\section{3. モデルの検証}

本報では一般的に身近で観察される互い違い形の渦列 についてモデルの検証をおこなう。対称形のモテルの検 証は本報ではおこなわない。

\section{$3-1$. 流脈線}

図 2 に検証にもちいた噴流の可視化実験装置を示す。 図2．（a）は装置全体図で、眝水タンクより流量調節弁 を通った水は整流タンクへ入る。整流タンクから吹き出 しノズルでは、 $30 \times 60 \times 550 \mathrm{~mm}$ の矩形の直線流路である 。そして絞りを通り $10 \times 60 \times 100 \mathrm{~mm}$ のノズルより噴出す る。図 2.（b）は噴流の流れ場の詳細図である。天井 板と床板に仕切られた、間隔 $60 \mathrm{~mm}$ の二次元の流れ場で ある。噴流の流れ場の可視化にはトレーサーにミルクを もちい、噴流の中心の流脈線と噴流の両側の剪断層に発 生する渦列 (流脈線) を可視化した。図 3 に噴流の可視化

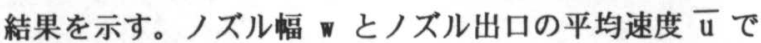
定義したレイノルズ数は $260 、 520 、 780$ である。ビデ オカメラの位置は $\mathrm{x} / \mathrm{w}=9$ 、シャッター速度は $1 / 250$ 秒である。トレーサーには市販されている牛乳の脂肪分 の多いものを用いた。ミルクで薄く白濁させた静止流体 の中へ、矩形断面のノズルより真水を噴出させた。噴流 の中心の黒い線はミルクである。Re. = 260 では、噴流 中心の流脈線が直線から波形に変わり、渦の中へ取り込

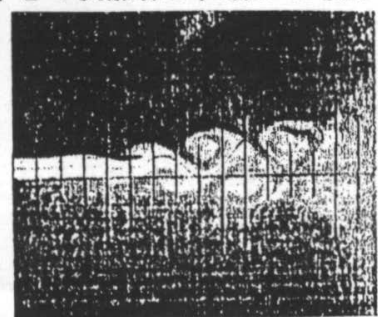

$\mathrm{t}=0 / 30 \mathrm{sec}$.

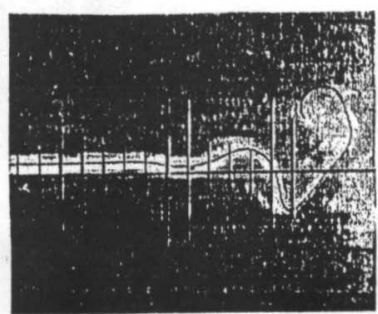

$\mathrm{t}=0 / 30 \mathrm{sec}$.

(1) : over flow water tank

(2): flow control valve

(3) : tank of uniforming of flow

(4): rectangular pipe

(5) : apparatus of visualization

(6) : video camera

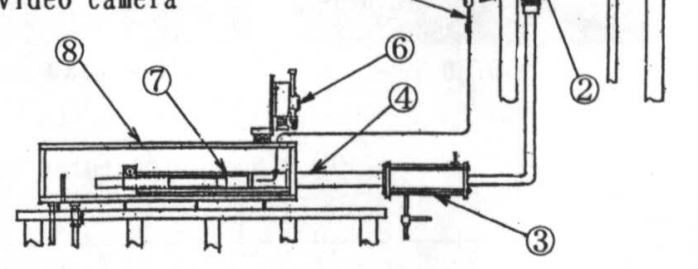

(a). Layout of experimental tow-dimensional jet

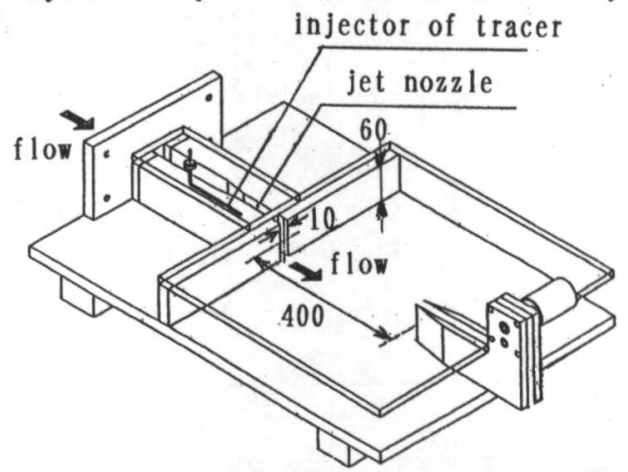

(b). Two-dimensional jet flow field (Detail diagram of (7))

Fig. 2 Schematic diagram of the experimental tow-dimensional jet

まれていく様子がわかる。また噴流の両側の剪断層に互 い違いの渦列が観察される。この連続影像は 14/30 秒 間隔の流脈線の対時応動である。観察される渦列は、後 流に発生する渦列より渦列の長さは短く、渦列はすぐに 崩壊にいたることがわかる。Re. =520 では、嘖流の中央 が渦へ巻き上がっていく様子がわかる。しかし y 方向

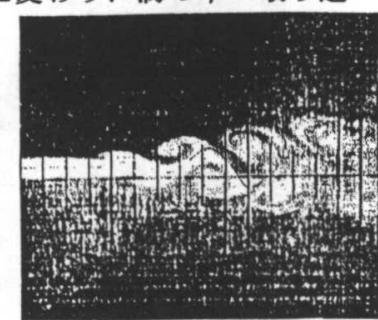

$\mathrm{t}=14 / 30 \mathrm{sec}$.

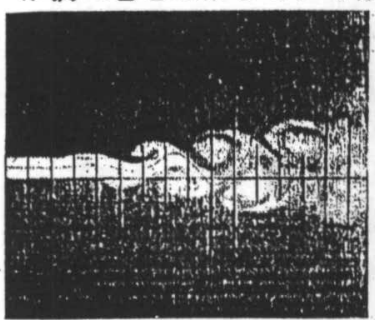

$\mathrm{t}=28 / 30 \mathrm{sec}$

(a) $\cdot \bar{u}=3 \mathrm{~cm} / \mathrm{s} \quad(\operatorname{Re} .=260)$

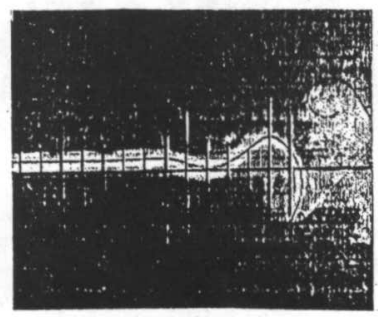

$\mathrm{t}=14 / 30 \mathrm{sec}$.

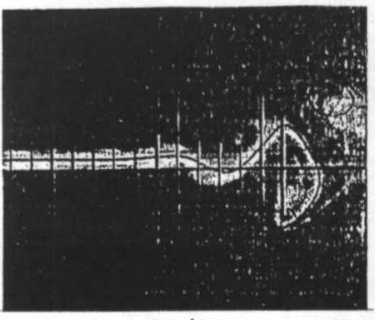

$\mathrm{t}=28 / 30 \mathrm{sec}$

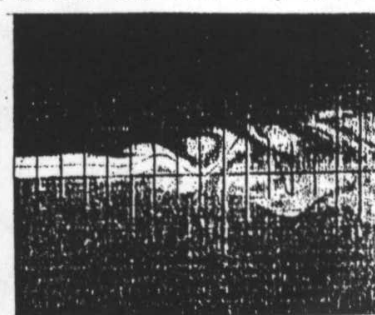

$\mathrm{t}=42 / 30 \mathrm{sec}$.

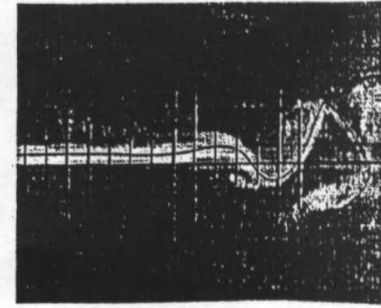

$\mathrm{t}=42 / 30 \mathrm{sec}$.

(b) $. \bar{u}=6 \mathrm{~cm} / \mathrm{s} \quad(\operatorname{Re} .=520)$ 


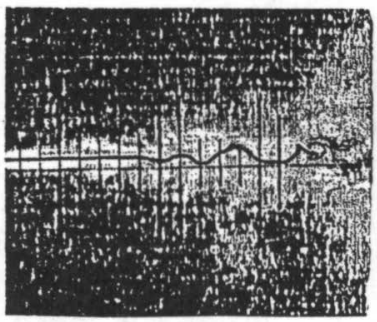

$\mathrm{t}=0 / 30 \mathrm{sec}$.

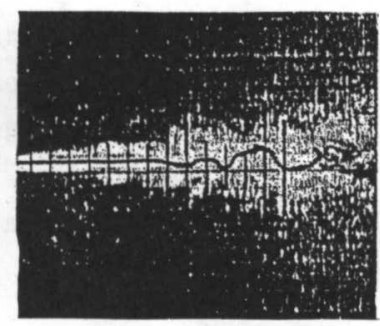

$\mathrm{t}=4 / 30 \mathrm{sec}$.

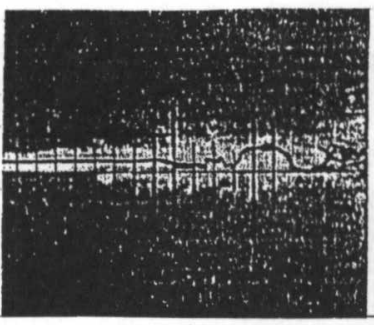

$\mathrm{t}=8 / 30 \mathrm{sec}$

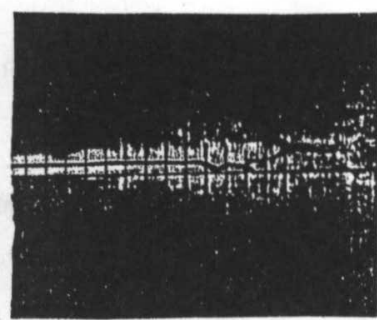

$\mathrm{t}=12 / 30 \mathrm{sec}$.

(c) $. \bar{u}=9 \mathrm{~cm} / \mathrm{s} \quad(\operatorname{Re} .=780)$

Fig. 3 Motion pictures of streak line, tow-dimensional free jet

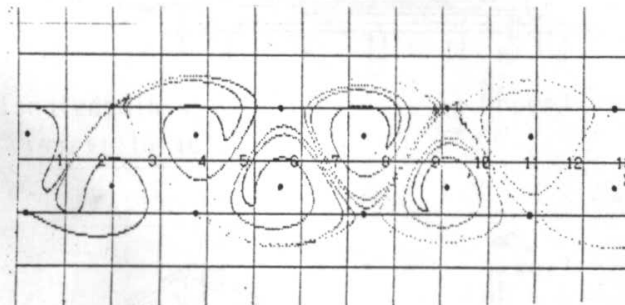

(a). $A=0.5$

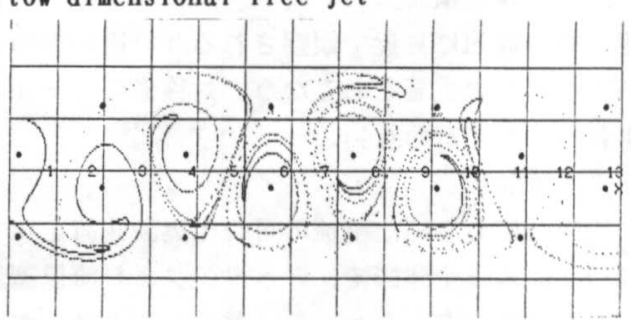

(b). $A=1.0$

Fig. 4 The calculative result of streak line, tow-dimensional free jet

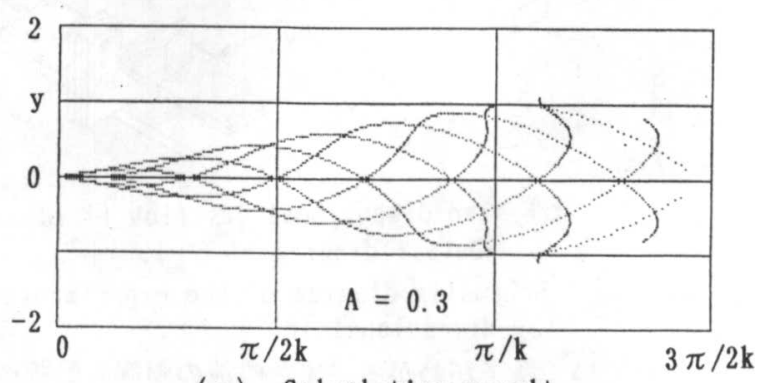

(a). Calculative result

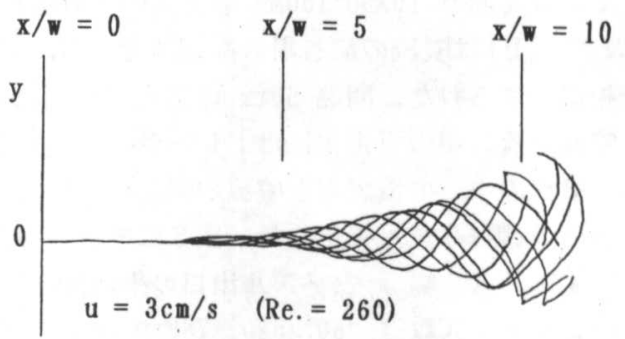

(b). Experimental result

Fig. 5 Motion pictures of streak line for center line of tow-dimensional free jet

への広がりが大きくなり渦列の長さはさらに短くなって

、一対の渦が観察されるだけである。Re.=780 では、

トレーサーに使用したミルクによる噴流の中央の流脈は 波形にはなるが、渦へ成長せず崩壊する。さらに嘖流の 両側の剪断層の幅が広がり、噴流の平行流れの部分が無 くなる。図 4 は波動モデルの計算結果である。摜乱の振 幅 $\mathrm{A}$ は $\overline{\mathrm{u}}_{\mathrm{c}}$ に対して一位の微小量であるので最大值を 1 にとった。 $A=1 、 0.5$ の場合の流脈線の計算結果で ある。完全流体の平行噴流の仮定の基でのモデルである ので平行な渦列がつずいている。しかし実驗結果の渦列 のつずく、レイノルズ数が 260 の場合とは定性的に一 致する。図 5 に噴流の中心の流脈線の対時応動を示す。 （a）は筧乱の振幅 $\mathrm{A}$ が 0.3 の場合の計算結果である。 (b) はレイノルズ数 260 の実験結果であり、ビデオ影 像の噴流の対時応動をトレースしたものである。両者は 定性的には似ている。

$3-2$. 噴流場のパワースペクトル

図 6 に噴流場の圧力変化のパワースペクトルの測定結 果の一例を示す。自由噴流場にエッジを入れるとある卓 越周波数が大きく生じることをしめしている。エッジの 無い場合の自由噴流場の圧力変化は、このような鲜明な 卓越周波数は無く、ゆるやかなピークを持つ。渦列を形
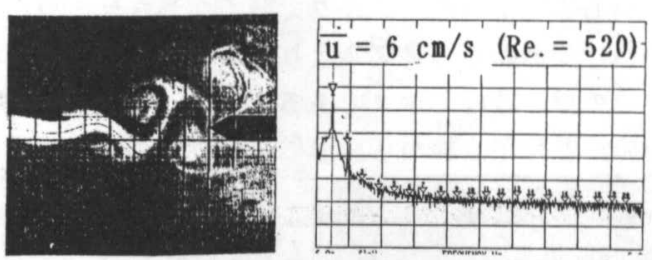

Fig. 6 Powerspectrum of pressure in flow field 成しても周期が変動する非常に不安定な流れ場であるこ とが推察できる。

\section{4. まとめ}

完全流体の二次元平行噴流の仮定の基に、非定常な噴 流の流れ場のモデ (線形モテル)を導いた。可視化実験 の結果と比較すると、噴流の両端の剪断層が平行で長く つずくときは、2 列の互い違いの渦列ができ、波動モテ ルと定性的に同じものとなる。噴流の中心軸の流脈線の 対時応動も定性的に似たフローパターンを示す。

\section{5. 参考文献}

1). Schlichting, Boundary Layer Theory, McGraw-Hill

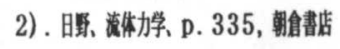
吥省糙 